\title{
- EPIDEMIOLOGY AND MORTALITY OF INVASIVE CANDIDIASIS IN HIGH RISK SURGICAL PATIENTS
}

Vidal-Seoane M, Pérez de Lis-Novo M, Yañez A, Martínez S, Fernandez-Carballal MF, Pensado-Castiñeiras A

\section{UNIVERSITY HOSPITAL LA GORUÑA, GALICIA, SPAIN}

\section{O BACKGROUND, MATERIAL AND METHODS}

Invasive Candidiasis (IC) is a frequent and life-threatening infection in critically ill patients.

The aim of this study was to evaluate the epidemiology of IC, antifungal susceptibility of aetiological agents and mortality of IC in high risk surgical patients Retrospective review of consecutive adult surgical patients with abdominal septic shock between June 12014 and April 302016 was conducted.

Preventive anidulafungin therapy was given until resolution of the surgical condition. Mortality was evaluated at the end of hospital stay and 30 days.

\section{RESULTS}

60 cases of IC were identified

23 women $(38 \%)$

37 men $(62 \%)$

Mean age 66 years ( $35-85)$ $100 \%$ IC were secondary peritonitis and severe sepsis or septic shock
Isolates:

C.Albicans 56\%, C.Parapsilosis 35\%,

C.Glabrata 16\%, C.Krusei $8 \%$, C.Tropicalis 5\% Ratio Non Albicans (26) - Albicans (34) was 1:1,3 In $15 \%$ isolates the candida was less susceptible or resistant to fluconazole

Resistance to other antifungals was uncommon

The crude mortality rate was $33 \%$

$44 \%$ in patients with candidemia

$80 \%$ patients with C.Krusei

Early mortality $26 \%$ Late mortality $6 \%$

\section{CONCLUSIONS}

Non-albicans candida species reach almost half of the candida isolates

Resistance to azoles should be considered when starting and empirical treatment.

Mortality of invasive candidiasis in ICU remains high and adequate antifungal therapy is necessary to lead a good outcome.

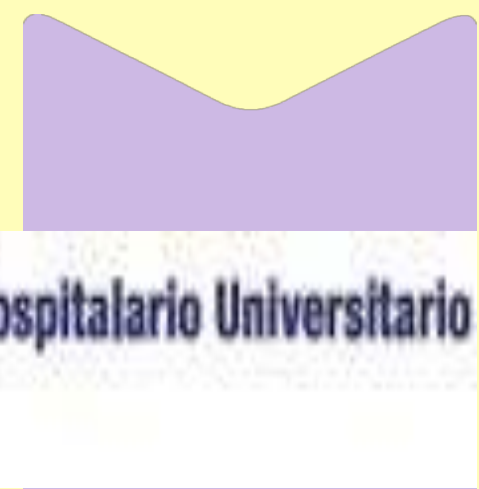

